\title{
AN EVALUATION OF THE JET INJECTOR (SANDERS) TECHNIQUE FOR BRONCHOSCOPY IN PAEDIATRIC PATIENTS
}

\author{
K. Miyasaka, I.A. Slonn and A.B. Froese
}

\begin{abstract}
The safety and efficacy of the jet injector (Sanders) technique for bronchoscopy in children was evaluated in a lung analogue and verified by clinical trial. Although the small internal diameters of paediatric bronchoscopes accommodate lower maximum flows, they also produce higher inflation pressures than adult bronchoscopes. It was found that even the smallest tapered bronchoscope ( $3 \mathrm{~mm}$ distal diameter) can compensate for flow limitations by producing high inflation pressures and can deliver tidal volumes of $6-9 \mathrm{ml} \cdot \mathrm{kg}^{-1}$ with a driving pressure of $276 \mathrm{kPa}$ ( $40 \mathrm{PSI}$ ).

However, in contrast to adult bronchoscopes, the function of paediatric bronchoscopes is vulnerable to small alterations in a number of variables. For example, in addition to the size of the jet and bronchoscope, the length and angle of the jet, the shape of the bronchoscope and the introduction of a suction cannula all have a significant influence on the maximal inflation pressures and therefore the volume of ventilation that can be produced.

During diagnostic bronchoscopy of 11 patients six months -3 years of age using the jet injector technique (Sanders \# 19) tidal volumes of $6-16 \mathrm{ml} \cdot \mathrm{kg}^{-1}$ were achieved through 3-6 $\mathrm{mm}$ ID tapered bronchoscopes using driving pressures of 138-276 kPa (20-40 PSI). Effective ventilation was achieved even in non-curarized patients. This is important since most of these patients have complex airway problems and the use of a muscle relaxant may be contraindicated.

It is important to note that these results are only applicable to the jet injector technique with the Sanders \# 19 adapter and any modifications to this should be carefully assessed.
\end{abstract}

THE ANAESTHETIC MANAGEMENT of bronchoscopy presents complex problems. The examination itself involves the airway directly; therefore, inevitably, the anaesthet ist and endoscopist must compete for access. Further, direct manipulation of the airway necessitates a fairly deep level of anaesthesia and consequently one can anticipate some degree of respiratory depression. In addition to thesc problems, smaller airway diameters produce higher airways resistance, while low respiratory compliance from associated lung disease can combine to make the maintenance of adequate ventilation during anaesthesia rather difficult in children.

Since the introduction of the Venturi jet injector technique by Sanders in 1967,' several authors have documented the adequacy of ventila-

K. Miyasaka, M.D., Department of Anaesthesia and Intensive Care Unit, National Children's Hospital, Tokyo, Japan. I.A. Sloan, M.B. M.D.(Cape), F.R.C.P.(C), Department of Anaesthesia, Hospital for Sick Children. A.B. Froese, M.D., F.R.C.P.(C), Department of Respiratory Physiology, Research Institute. Hospital for Sick Children, Toronto, Ontario.

Reprint address: Dr. Alison Froese, Room 4531, Respiratory Physiology, Hospital for Sick Children, 555 University Avenue. Toronto, Ontario, Canada, MSG IX8. tion and convenience of the technique in adults ${ }^{2.3}$ It has been established by Spoerel and Grant that the peak inflating pressures and maximal flows are related to the driving pressure, size of the injector, internal diameter of the bronchoscope and the relationship of cricoid dimensions to external diameter of the bronchoscope. 4 Jardine, Harrison and Healy have also explored in a lung model the influence of changes in "patient" airway resistance and lung compliance on entrainment ratios and the resulting delivered oxygen concentrations and tidal volume. ${ }^{5}$

These investigations have clarified many of the inter-relationships affecting the operation of jet injector systems and provided the knowledge required for their safe effective use. However, reports of the application of the jet injector technique in a paediatric population are fragmentary. Bethune, Collis, Burbridge and Forster recommended that one use a fixed driving pressure of 60 psi $(413 \mathrm{kPa})$ and choose an injector of such a size that the maximal airway pressure would be $15-18$ $\mathrm{cm} \mathrm{H}_{2} \mathrm{O}(1.5-1.8 \mathrm{kPa})$ with paediatric bronchoscopes. ${ }^{6}$ No clinical trials were made, but one can predict that artificial ventilation will be inadequate with these pressure limits in many children with respiratory pathology. Brown documented a 
TABLE I

Specifications of Paediatric Bronchoscopes

\begin{tabular}{|c|c|c|c|c|}
\hline \multirow[b]{2}{*}{ Size } & \multirow[b]{2}{*}{ Type } & \multirow{2}{*}{$\begin{array}{c}\text { Internal } \\
\text { diameter } \\
\text { distal portion } \\
(\mathrm{mm})\end{array}$} & \multicolumn{2}{|c|}{ Resistance (at $601 / \mathrm{min}$ ) } \\
\hline & & & $\left(\mathrm{kPa} / 1 \cdot \mathrm{min}^{-1}\right)$ & $\left(\mathrm{cmH}_{2} \mathrm{O} / 1 \cdot \min ^{-1}\right)$ \\
\hline $3 \times 26$ & Jackson & $3 \mathrm{~mm}$ & 8.83 & 90 \\
\hline $4 \times 20$ & Hollinger & $4 \mathrm{~mm}$ & 4.12 & 42 \\
\hline $5 \times 35$ & Jackson & $5 \mathrm{~mm}$ & 2.45 & 25 \\
\hline $6 \times 40$ & Hollinger & $6 \mathrm{~mm}$ & 2.16 & 22 \\
\hline
\end{tabular}

linear relationship between driving pressure and maximal intratracheal pressure using an infant Negus bronchoscope in puppies with an unstated injector size. ${ }^{7}$ Although he recommended the use of a variable pressure source he put a low limit on it of $20 \mathrm{psi}(138 \mathrm{kPa})$ maximum.

Spoerel, et al. ${ }^{4}$ demonstrated that the maximum pressure attainable with a given jet size and driving pressure was inversely related to the cross-sectional area of the tube. Furthermore, they noted the influence of the shape of a bronchoscope on inflation pressures: a $6 \mathrm{~mm}$ bronchoscope of uniform diameter throughout achieved much higher inflation pressures than a tapered type of bronchoscope that was $6 \mathrm{~mm}$ in diameter distally but wider at the proximal end where the injector is positioned. With small paediatric bronchoscopes a marked taper is common and the intrinsic resistance of the bronchoscope is much higher than in the adult ones. These features make one question whether the injector system can in fact achieve adequate ventilation in small children with lung pathology whose airway resistance is high and lung compliance low.

This study was therefore designed with the following objectives:

1. To determine the influence of bronchoscope shape on pressure and flow relationships using a jet injector in a lung analogue.

2. To determine in the lung analogue whether adequate tidal volumes can be delivered using the injector system in the presence of abnormalities of airways resistance and compliance.

3. To explore in a lung analogue the risk of developing excessive airway pressures.

4. To determine the adequacy of the ventilation delivered to paediatric patients undergoing diagnostic bronchoscopy both with and without the use of muscle relaxants.

\section{METHOD}

\section{A. Evaluation using lung analogue}

A test lung system with adjustable resistance and compliance was used. Resistance was varied by changing the diameter of a plastic tube that connected the bronchoscope to a large bottle, the volume of which was altered to achieve the desired range of compliances. The bronchoscope was sealed tightly into the "trachea" of this test lung. Airway pressure was measured using a pressure gauge (Ohio). Flow rates and tidal volumes were measured using a pneumotachograph (Fleisch \#2). $\mathrm{Fl}_{\mathrm{O}_{2}}$ was measured using a mass spectrometer (Medispect). All measurements except $\mathrm{FI}_{\mathrm{O}_{2}}$ were made using air as the driving gas at room temperature. Repeat measurements showed little variation. Values quoted are the means of three replicate mcasurements. A Bird Mark VIII respirator was modified for these experiments for the automatic delivery of an intermittent flow of gas, with inspiratory time and driving pressure independently controlled.

Influence of bronchoscope shape: Tapered paediatric bronchoscopes, the preferred instruments on this hospital's large paediatric otolaryngology service (Table I), and straight tracheal tubes of similar internal diameter and size were used to determine the influence of size and shape on pressure/flow characteristics. A teflon catheter (\#20 Angiocath) was aligned axially and used as a jet with $345 \mathrm{kPa}$ (50 psi) driving pressure.

Adequacy of volumes delivered: The pressure/flow characteristics of tapered bronchoscopes $(3,4,5$ and $6 \mathrm{~mm}$ distal internal diameters) were determined using a commercially produced Sanders \# 19 adapter. Maximum plateau pressures were measured in the "lung" over a range of driving pressures from 138 to $345 \mathrm{kPa}$ (20 to 50 
psi). Maximum flows were measured for all four sizes of bronchoscope with no added resistance, and also with 2.9 and $9.8 \mathrm{kPa} / \mathrm{l} \cdot \mathrm{sec}^{-1}$ (30 and 100 $\mathrm{cm} \mathrm{H}_{2} \mathrm{O} / 1 \cdot \mathrm{sec}^{-1}$ ) of additional downstream resistance. The tidal volumes delivered to the test lung were measured over a range of driving pressures with one second inflation times using values of resistance of $0.29 \mathrm{kPa} / 1 \cdot \mathrm{sec}^{-1}(3 \mathrm{~cm}$ $\left.\mathrm{H}_{2} \mathrm{O} / 1 \cdot \mathrm{sec}^{-1}\right)$ and a compliance of $0.21 / \mathrm{kPa}(0.02$ $1 / \mathrm{cm} \mathrm{H}_{2} \mathrm{O}$ ) to model a "good" lung and values of $\mathrm{R}=2.94 \mathrm{kPa} / 1 \cdot \mathrm{sec}^{-1}\left(30 \mathrm{~cm} \mathrm{H} \mathrm{H}_{2} \mathrm{O} / \mathrm{l} \cdot \mathrm{sec}^{-1}\right) \mathrm{C}=$ $0.051 / \mathrm{kPa}\left(0.005 \mathrm{l} / \mathrm{cm} \mathrm{H}_{2} \mathrm{O}\right)$ to mimic a lung with severe pathology.

Risk of excessive pressures: The relationship of the depth of insertion of the tip of the jet and the maximum inflation pressure was studied with 3 $\mathrm{mm}$ straight and tapered bronchoscopes with a \#20 jet and $345 \mathrm{kPa}$ (50 psi) driving pressure. Jet position varied between 0.5 and $4 \mathrm{~cm}$ from the proximal ends. The effect of the insertion of suction cannulae on inflation pressure was studied on the tapered bronchoscopes only. Both large (\#12 French) and small (\#6 French) metal suction cannulae were advanced stepwise through the bronchoscopes while pressure was recorded. The influence of jet alignment on inflation pressure was determined by measuring inflation pressures at $345 \mathrm{kPa}(50 \mathrm{psi})$ while varying the angle of alignment relative to the bronchoscope axis between 0 and $6^{\circ}$.

\section{B. Clinical trial}

Eleven patients scheduled for elective diagnostic bronchoscopy were studied. Their ages ranged from six months to three years. The protocol of the study was reviewed by an institutional human experimentation committee that ruled that specific consent was not required. A continuous record of the patients' respired volumes was obtained using a jacket plethysmograph. This is an air-filled, double layered polyurethane coated nylon jacket which is placed on the subject, covering him from the sternal notch to the symphysis pubis. The logarithm of the pressure recorded in the jacket is linearly related to the lung volume changes of the patient. A detailed description of the performance of this jacket has been published. ${ }^{8}$

No premedication was given. Anaesthesia was induced and maintained with 50 per cent nitrous oxide with oxygen and 1-2 per cent halothane and/or 0.5-1.0 per cent methoxyflurane.

Following induction a topical spray of lidocaine, up to $3 \mathrm{mg} \cdot \mathrm{kg}^{-1}$ was applied to the

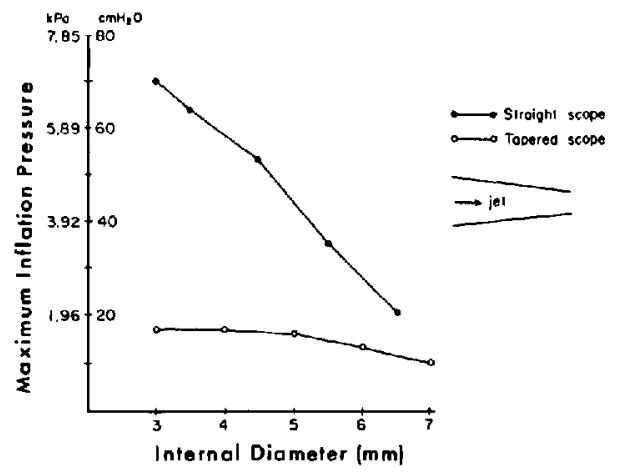

FIGURE I Relationship of the maximum inflation pressure and internal diameter for both straight and tapered bronchoscopes. Driving pressure $345 \mathrm{kPa}$ (50 psi). Jet size \#20. A strong dependence of inflation pressure on size occurs only with the straight bronchoscopes.

larynx and trachea. Routine bronchoscopic examination was carried out with the patient breathing spontaneously. At the end of the examination six of the patients then received succinylcholine $1.0 \mathrm{mg} \cdot \mathrm{kg}^{-1}$ and atropine 0.01 $\mathrm{mg} \cdot \mathrm{kg}^{-1}$ intravenously. The Sanders adapter (\#19) was then attached to the bronchoscope and driving pressure was adjusted to deliver approximately $10 \mathrm{ml} \cdot \mathrm{kg}^{-1}$ of tidal volume as determined from the respiratory jacket reading. In five patients jet ventilation was attempted without the use of any muscle relaxants. In four patients, airway pressure at the end of the bronchoscope was measured directly by passing a small bore catheter connected to a pressure gauge through the bronchoscope.

\section{RESULTS}

The specifications of the paediatric bronchoscopes used in this study are given in Table $\mathbf{I}$.

\section{A. Evaluation using lung analogue}

Influence of bronchoscope shape: The relationship between the size and shape of bronchoscopes and the maximum inflation pressure is shown in Figure 1. Using a constant jet size (\#20 gauge) and driving pressure of $345 \mathrm{kPa}(50 \mathrm{psi})$. The inflation pressure plateau increases sharply from 1.96 to $6.9 \mathrm{kPa}\left(20\right.$ to $\left.70 \mathrm{~cm} \mathrm{H} \mathrm{H}_{2} \mathrm{O}\right)$ as the diameter of a straight tube decreases from $6.5 \mathrm{~mm}$ to $3.0 \mathrm{~mm}$. This effect is almost abolished with tapered bronchoscopes.

The relationship between bronchoscope size 


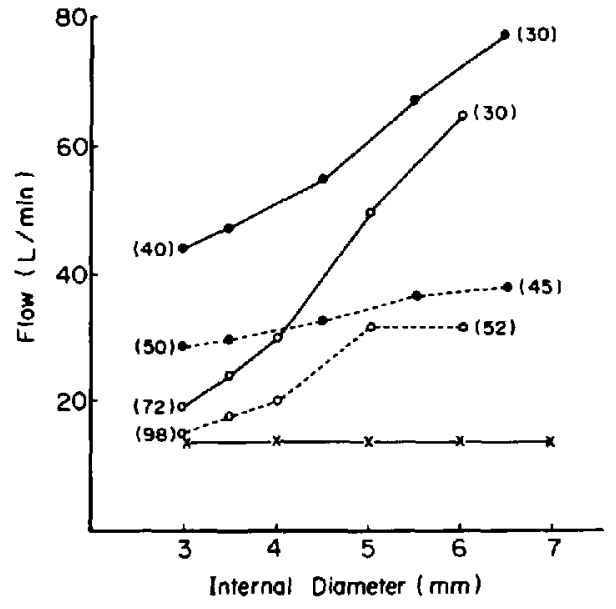

FIGURE 2 Relationship of maximal flow to internal diameter with a fixed driving pressure of $345 \mathrm{kPa}$ ( $50 \mathrm{psi}$ ) and $\# 20$ jet. $=$ straight bronchoscopes. $\mathrm{O}=$ tapered bronchoscopes. A solid line joins values obtained with no added resistance. Dashed lines join points obtained with the resistance of the test lung increased by $2.94 \mathrm{kPa} / \mathrm{l} \cdot \mathrm{sec}^{-1}\left(30 \mathrm{~cm} \mathrm{H} \mathrm{H}_{2} \mathrm{O} / \mathrm{l} \cdot \mathrm{sec}^{-1}\right)$. $x-x$ represents flow through the jet alone. Bracketed values are the percentages of oxygen delivered to the test lung.

and maximal flow at constant jet size and driving pressures is presented in Figure 2 for both straight and tapered bronchoscopes. The straight line at the bottom represents the flow from the jet alone. Any value above this reflects air entrainment which is responsible for the decreases in $\mathrm{FI}_{\mathrm{O}_{2}}$ evident at high flow rates. When airway resistance is at a minimum, an increase in diameter results in an increase in maximum flow that is most marked with the tapered bronchoscopes. Maximum flow rates were always much lower through a tapered bronchoscope than a straight one of the same diameter, with the discrepancy being most marked in the smaller sizes. Both types of bronchoscope evidenced a sharp decrease in maximum flow rates when a 2.9 $\mathrm{kPa} / 1 \cdot \mathrm{sec}^{-1}$ ( $30 \mathrm{~cm} \mathrm{H}_{2} \mathrm{O} / \mathrm{l} \cdot \mathrm{sec}^{-1}$ ) external resistance was added. This effect was greater with the $6 \mathrm{~mm}$ tapered bronchoscope while the $3 \mathrm{~mm}$ tapered bronchoscope showed less sensitivity to added resistance.

Adequacy of volumes delivered: Maximum pressure plateaus from 138 to $345 \mathrm{kPa}$ (20 to 50 psi) driving pressure are shown in Figure 3(a) for four sizes of tapered bronchoscopes. Maximum pressures are inversely related to internal diameter, with values of $4.2 \mathrm{kPa}\left(43 \mathrm{~cm} \mathrm{H} \mathrm{H}_{2} \mathrm{O}\right)$ being obtained with a $3 \mathrm{~mm}$ bronchoscope com-

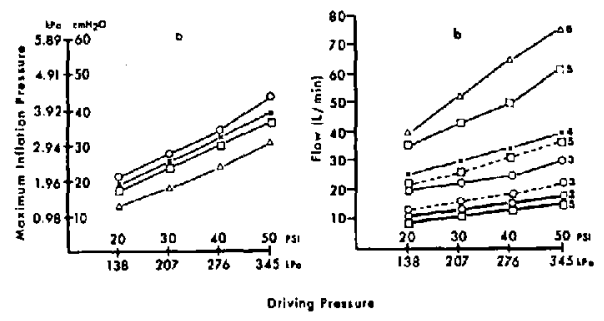

Figure 3a Maximal inflation pressures obtained over a range of driving pressures with four sizes of tapered bronchoscopes and a \# 19 Sanders adapter. In this and subsequent figures. consistent symbols are used: $0-0,3 \mathrm{~mm}$ internal diameter, $26 \mathrm{~cm}$ length. $x \rightarrow \times .4 \mathrm{~mm}$ by $20 \mathrm{~cm}$. $\square-\square .5 \mathrm{~mm}$ by $35 \mathrm{~cm} . \Delta-\Delta$. $6 \mathrm{~mm}$ by $40 \mathrm{~cm}$.

Figure 3b Variations in maximal flow over a range of driving pressures. Solid lines give results using tapered bronchoscopes with no added resistance. Dashed lines = flow rates after addition of $2.94 \mathrm{kPa} / \mathrm{l} \cdot \mathrm{sec}^{-1}$ $\left(30 \mathrm{~cm} \mathrm{H} \mathrm{H}_{2} \mathrm{O} / \mathrm{l} \cdot \mathrm{sec}^{-1}\right)$ resistance. Heavy lines = flow rates after the addition of $9.81 \mathrm{kPa} / \mathrm{l} \cdot \mathrm{sec}^{-1}(100 \mathrm{~cm}$ $\left.\mathrm{H}, \mathrm{O} / 1 \cdot \mathrm{sec}^{-1}\right)$ resistance. Note the reversal of the relative positions of 3 and $5 \mathrm{~mm}$ bronchoscopes when the added resistance is very large.

pared to $2.9 \mathrm{kPa}\left(30 \mathrm{~cm} \mathrm{H}_{2} \mathrm{O}\right)$ for a $6 \mathrm{~mm}$ one at the same $345 \mathrm{kPa}$ ( $50 \mathrm{psi}$ ) driving pressure. Figure 3(b) demonstrates a linear relationship between driving pressure and maximum flow. In the absence of any external resistance there is a 150 per cent increase in flow with a change from a $3 \mathrm{~mm}$ to a $6 \mathrm{~mm}$ internal diameter at $345 \mathrm{kPa}$ (50 psi) driving pressure. However, these differences in function shrink in the face of added resistance. With $9.8 \mathrm{kPa} / \mathrm{l} \cdot \mathrm{sec}^{-1}\left(100 \mathrm{~cm} \mathrm{H}_{2} \mathrm{O} / \mathrm{l} \cdot \mathrm{sec}^{-1}\right)$ added there is a reversal of the relative positions of the bronchoscopes with flow through a $3 \mathrm{~mm}$ bronchoscope actually exceeding that through a 5 mm one.

The tidal volumes achieved using one second inflation periods are shown in Figure 4 for "good" and "sick" test lung conditions. In the "good" lung, bigger bronchoscopes tend to deliver higher tidal volumes, but the overall difference in volume is small. In the "poor" lung, all the bronchoscopes deliver almost identical tidal volumes, which in all cases exceeded $100 \mathrm{ml}$ with a driving pressure of $207 \mathrm{kPa}$ ( $30 \mathrm{psi}$ ). The inspired oxygen concentration at the test airway was always above 50 per cent in this experiment.

Risk of excessive pressure: A minimal influence of jet location on maximum inflation pressure was seen with a straight bronchoscope (Figure 5). However, using a $3 \mathrm{~mm}$ tapered bronchoscope, a threefold increase in maximum pres- 


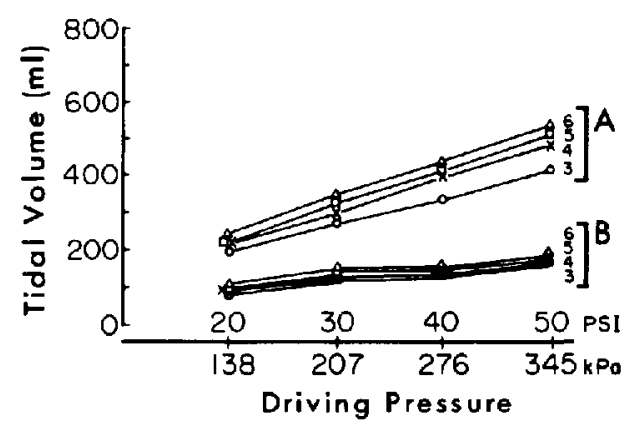

FIGURE 4 Tidal volume delivered to a test lung using the same lapered bronchoscopes over a range of driving pressures, using a \#19 Sanders adapter. Inspiratory duration was one second in all cases. Group A: Test lung compliance $(C)=0.201 / \mathrm{kPa}(0.021 / \mathrm{cm}$ $\left.\mathrm{H}_{2} \mathrm{O}\right)$, and Resistance $(\mathrm{R})=0.29 \mathrm{kPa} / \mathrm{l} \cdot \mathrm{sec}^{-1}(3 \mathrm{~cm}$ $\left.\mathrm{H}_{2} \mathrm{O} / \mathrm{l} \cdot \mathrm{sec}^{-1}\right)$. Group B: $\mathrm{C}=0.05 \mathrm{I} / \mathrm{kPa}\left(.005 \mathrm{l} / \mathrm{cm} \mathrm{H}_{2} \mathrm{O}\right)$ $R=2.94 \mathrm{kPa} / \mathrm{l} \cdot \mathrm{sec}^{-1}\left(30 \mathrm{~cm} \mathrm{H} \mathrm{H}_{2} \mathrm{O} / \mathrm{l} \cdot \mathrm{sec}^{-1}\right)$. Numbers beside the lines indicate internal bronchoscope diameters.

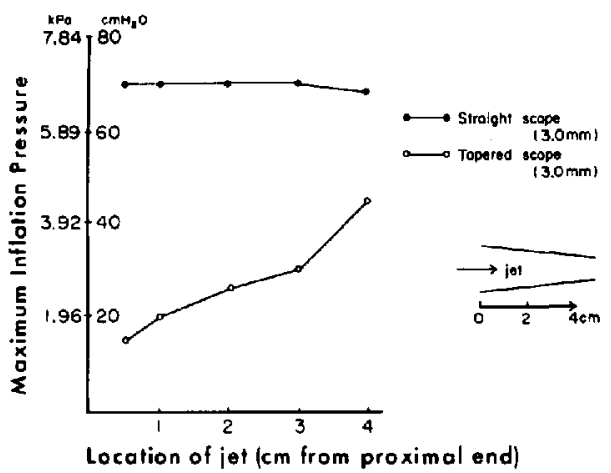

FIGURE 5 Influence of jet location on maximum inflation pressure. Driving pressure $345 \mathrm{kPa}(50 \mathrm{psi})$ with \#20 gauge jet. The schematic indicates a jet with the tip located about $7 \mathrm{~mm}$ from the proximal end. Note the large variations in inflation pressure when jet location is varied in a tapered bronchoscope.

sure resulted when the jet location was altered over a $4.5 \mathrm{~cm}$ distance. This occurred because the internal diameter of the bronchoscope where the jet was introduced became progressively smaller as the jet tip was advanced.

Pressure variations associated with the insertion of suction cannulae are shown in Figure 6. Pressure changes ranging from -40 per cent to +40 per cent occur, depending on the relative size of cannula and bronchoscope at each depth of penetration. The numbers in parentheses give values for absolute pressure. With a $3 \mathrm{~mm}$ tapered bronchoscope and a small (6F) suction

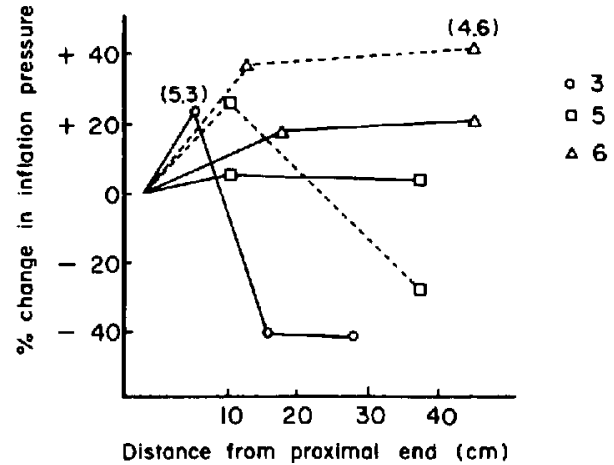

Figure 6 Effect of the insertion of suction cannulae into tapered bronchoscopes using a $345 \mathrm{kPa}$ (50 psi) driving pressure and \# 19 Sanders adapter. Alterations in maximal inflation pressure are expressed as percentage changes. Solid line indicates insertion of a small (\#6 French) suction cannula. Dashed line indicates the large (\#12 French) cannula. Absolute maximal values observed are shown in brackets (in $\mathrm{kPa}$ ).

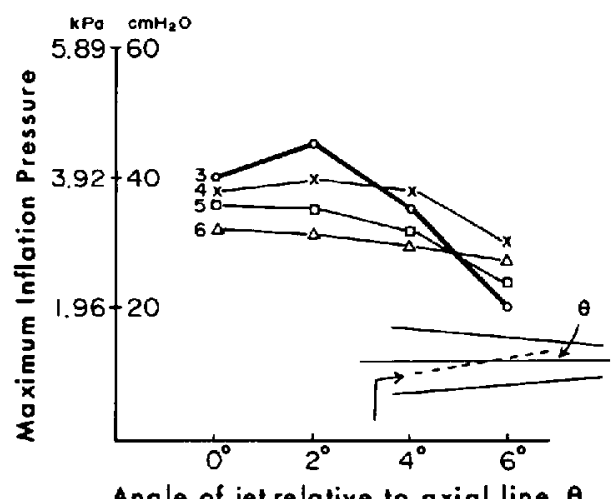

Angle of jel relative to axial line $\theta$

FIGURE 7 Relationship of maximal inflation pressure to the angle at which the jet is inserted into tapered bronchoscopes $(3,4,5$, and $6 \mathrm{~mm} I D)$.

cannula, the inflation pressure increased 24 per cent at a depth of $8 \mathrm{~cm}$ but then decreased drastically to -40 per cent with further insertion of the cannula. With a $6 \mathrm{~mm}$ bronchoscope and a large cannula $(12 \mathrm{~F})$ the inflation pressure increased rapidly by 35 per cent at $12 \mathrm{~cm}$ from the orifice, with a gradual increase to 40 per cent as the cannula advanced to the end.

Figure 7 illustrates the effect of the angle of the jet and inflation pressure. The inflation pressure tends to be highest when the jet is parallel to the axial line. When the size of the bronchoscope is small, this relationship is most critical. In a $3 \mathrm{~mm}$ bronchoscope, a $6^{\circ}$ deviation from the axial line caused a 50 per cent reduction in inflation pres- 


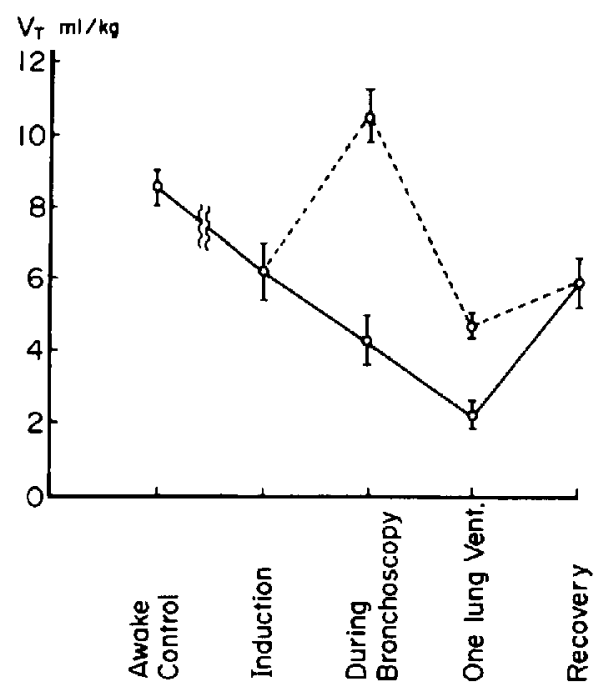

FigURE 8 Tidal volumes (mean \pm SD) measured at various stages of the procedure using a jacket plethysmograph. Control values were derived from a separate group of awake unmedicated children of similar age and weight. Solid line joins values obtained during spontaneous respiration; dashed line joins values using the jet injector.

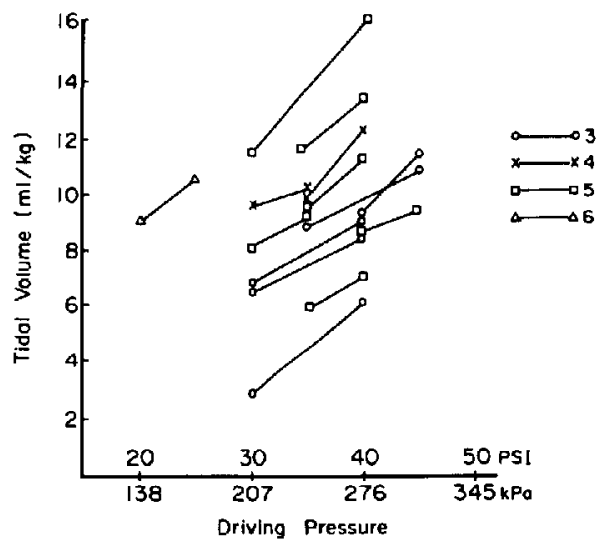

Figure 9 Relationship of tidal volume delivered and driving pressure during 14 trials in 11 patients. Symbols indicate the relevant bronchoscope size.

sure, but in the case of a $6 \mathrm{~mm}$ bronchoscope only a 10 per cent reduction resulted.

\section{B. Clinical trial}

Mean values for tidal volume over the course of general anaesthesia are given in Figure 8 for 11 children (mean weight $10.1 \mathrm{~kg}$ ). The control value was taken from measurements made on 12 healthy awake subjects of the same age range using the same jacket plethysmograph method. Shortly after the induction of anaesthesia, tidal volume fell to a mean of $6.2 \mathrm{ml} / \mathrm{kg}$. By the time conditions were suitable for the bronchoscopic examination, mean tidal volume fell to $4.2 \mathrm{ml} / \mathrm{kg}$. Concurrently, the respiratory rate increased to a mean of $45 / \mathrm{min}$ from the control value of $37 / \mathrm{min}$. The dotted line represents the tidal volumes achieved using the Venturi technique. The average tidal volume exceeded $10 \mathrm{ml} / \mathrm{kg}$ using this method. During one lung ventilation tidal volumes were approximately $5 \mathrm{ml} / \mathrm{kg}$ using the injector compared to $2 \mathrm{ml} / \mathrm{kg}$ with unaided spontaneous respiration. Ventilation was readily controlled in all five patients in whom no muscle relaxant was used.

Figure 9 summarizes the relationship between tidal volume and driving pressure in our 11 patients during 14 trials. Adequate tidal volumes were achieved with driving pressures between 138 and $310 \mathrm{kPa}$ (20 and $45 \mathrm{psi}$ ). Direct measurements of intratracheal pressure in four patients confirmed the relationships between driving pressure and inflation pressure as determined in the lung model.

\section{Discussion}

This investigation demonstrates that ventilation of paediatric patients using the jet injector technique can be both safe and effective, even without the use of muscle relaxants. However, the significance of bronchoscope shape with respect to its functional characteristics must be recognised, since most paediatric bronchoscopes are now of the tapered type.

As shown in Figure 1, with straight bronchoscopes the maximum inflation pressure is influenced markedly by size (as demonstrated by Spoerel, et al., for adult bronchoscopes ${ }^{4}$ ) but is unaffected by changing the depth of penetration of the jet. The situation is reversed with tapered bronchoscopes. Now size has little influence on maximum inflation pressure because in all tapered bronchoscopes the diameter at the site of jet insertion is almost identical. However, these bronchoscopes are very sensitive to the depth of penetration of the jet (Figure 5) since if the tip of the jet is advanced through the tapered portion the internal diameter rapidly decreases and the inflation pressure progressively increases.

If one introduces a suction cannula, the place where the jet is introduced becomes smaller, producing increased inflation pressure. This effect 
was large only with $5 \mathrm{~mm}$ and $6 \mathrm{~mm}$ bronchoscopes where the absolute maximum pressure reached $5.3 \mathrm{kPa}\left(54 \mathrm{~cm} \mathrm{H} \mathrm{H}_{2} \mathrm{O}\right)$. In smaller $3 \mathrm{~mm}$ bronchoscopes, further advancement of the suction cannula produced a significant increase in airway resistance distal to the jet, thus decreasing inflation pressure to ineffectual levels (Figure 6). It is difficult to determine what constitutes a safe limit to airway pressure, but the maximum inflation pressures found in our study are probably not dangerous if applied only briefly. In actual clinical use it is important to keep this characteristic in mind and to have an additional margin of safety one might choose to interrupt jet flow while the suction cannula is in place.

It has been emphasized that the size of the jet and the driving pressure are important in determining inflation pressure but, as can be seen from Figure 5 and Figure 7, the length and angle of the jet are equally important. If modifications are made to a Sanders adapter such that the length of the jet is increased, as suggested by Komesaroff \& $\mathrm{McKie}^{9}$ inflation pressures will become too high unless driving pressure is reduced (Figure 5). The smaller paediatric bronchoscope is very vulnerable to the angle of the jet (Figure 7). A tiny change in jet angle may cause a 50 per cent reduction in inflation pressure to $2 \mathrm{kPa}\left(20 \mathrm{~cm} \mathrm{H} \mathrm{H}_{2} \mathrm{O}\right)$ inflation pressure using a $3 \mathrm{~mm}$ tapered bronchoscope. This might be insufficient to ventilate a patient with poor lungs.

Another concern has been the possible occurrence of excessive pressures, especially in children where bronchoscopes tend to fit snugly, if the proximal end is accidentally obstructed. ${ }^{4}$ In such a circumstance it should be theoretically possible to produce intrathoracic pressures equal to the driving pressure $(138-345 \mathrm{kPa}$ or $20-50$ psi). However, this was not the case with the Sanders adapter because of multiple vent holes in the side and its rough surface. When attempts were made to close off the proximal end of a Sanders adapter, the inflation pressure remained virtually constant.

To assess the adequacy of the venturi technique one must consider the pressure-flow characteristics of the injector in conjunction with the preferred bronchoscope types presently in use. It is evident from Figure 3 that smaller tapered bronchoscopes have the advantage with respect to maximal inflation pressures, while the larger ones can deliver much higher maximal flows in the absence of any downstream resistance. When tested in a lung model the flow limitations of the $3 \mathrm{~mm}$ bronchoscope are evident with the "good" lung (Figure 4). However, once pulmonary pathology is present $(\mathrm{C}=0.05 \mathrm{l} / \mathrm{kPa}$ or $0.005 \mathrm{l} / \mathrm{cm} \mathrm{H} \mathrm{m}_{2} \mathrm{O}, \mathrm{R}=2.9 \mathrm{kPa} / \mathrm{l} \cdot \mathrm{sec}^{-1}$ or $30 \mathrm{~cm}$ $\mathrm{H}_{2} \mathrm{O} / 1 \cdot \mathrm{sec}^{-1}$ ) it is evident that the maximal inflation pressures determine the practical limit to ventilation with the injector. Therefore tidal volumes with the $3 \mathrm{~mm}$ bronchoscope almost equal those delivered by the $5 \mathrm{~mm}$ one. From Figure 3B one can conclude that, with extremely high airways resistance, the $3 \mathrm{~mm}$ bronchoscope would actually be more effective than the $5 \mathrm{~mm}$. These observations are in agreement with the analysis of injector performance by Mushin, RendellBaker, Thompson \& Mapleson where injectors are classified as constant pressure generators in series with a resistance. ${ }^{10}$ Therefore one would expect the patient's respiratory compliance to be the main determinant of tidal ventilation. In the model, even the extreme values for a "sick" paediatric lung. tidal volumes of over $100 \mathrm{ml}$ were readily achieved with all bronchoscopes (3-6 $\mathrm{mm}$ size), indicating that the Sanders Injector should be capable of providing adequate ventilation in virtually any paediatric case.

The clinical trial verified the efficacy of the injector technique. We recognize that many diagnostic bronchoscopies and bronchoscopies for removal of foreign body are best managed using a technique that allows spontaneous ventilation. However, for those difficult patients with respiratory failure and/or stiff lungs, the jet injector should provide an effective method of ventilatory management for both diagnostic and therapeutic bronchoscopies. Rather than having to rely on a second order variable (blood gases), as have most adult studies, the respiratory jacket allowed us to assess directly the actual tidal volumes delivered. Even without muscle relaxants ( 5 of the 11 cases) tidal volumes exceeding $10 \mathrm{ml} / \mathrm{kg}$ were readily achieved in all cases using driving pressures of 166-310 kPa (24-45 psi) (Figure 9). These are levels of driving pressure readily available in any hospital.

\section{REFERENCES}

1. Sanders, R.D. Two ventilating attachments for bronchoscopes. Delaware Med. J. 39: 170 (1967).

2. SPOEREL, W.E. Ventilation through an open bronchoscope. Can. Anaes. Soc. J. 16:61 (1969).

3. Giesecke, A.H., Gerbshagen, H.U., Dortman, C. \& LEE, D. Comparison of the ventilating and injection bronchoscopes. Anesthesiology 38: 298 (1973).

4. SPoerel, W.E. \& Grant, P.A. Ventilation during bronchoscopy. Can. Anaes. Soc. J. 18: 178 (1971). 
5. Jardine, A.D.. Harrison, M.J. \& Healy, T.E.J. Automatic flow interruption bronchoscope: a laboratory study. Br. J. Anaesth. 47: 385 (1975).

6. Bethune, D.W.. Collis, J.M., Burbridge, N.J. \& Forster, D.M. Bronchoscope injectors. Anaesthesia 27: 81 (1972).

7. Brown, T.C.K. The Venturi bronchoscopic attachment - paediatric considerations. Anaesth. Intens. Care 1: 54 (1972).

8. Kattan, M., Miyasaka. K., Volgyesi, G. \& Froese, A.B. A respiratory jacket for ventilatory measurements in children. J. Appl. Physiol. Respirat. Environ. Exercise Physiol. 45: 630 (1978).

9. Komesaroff, D. \& MCKIE, B. The "Bronchoflator": a new technique for bronchoscopy under general anaesthesia. Br. J. Anaesth. 44:1057 (1972).

10. Mushin, W.W.. Rendell-Baker, L., ThompSON, P.W. \& MAPLESON, W.W. Automatic ventilation of the lungs. 2nd ed. Oxford and Edinburgh: Blackwell Scientific Publication. pp 86-88 (1969).

\section{RÉSUMÉ}

L'efficacité et la sécurité de la ventilation à l'injecteur de Sanders utilisée dans les cas de bronchoscopie chez l'enfant, ont été évaluées sur un montage en laboratoire, ainsi qu'en clinique. Les bronchoscopes de calibre pédiatrique n'admettent que des injecteurs de petit calibre, ce qui limite le débit gazeux tout en produisant des pressions plus élevées que celles urilisées chez l'adulte.

On a trouvé que même avec les plus petits bronchoscopes ( $3 \mathrm{~mm}$ de diamètre interne), les limitations de débit étaient compensées par la haute pression du jet, des volumes courants de 6 à $9 \mathrm{ml} \cdot \mathrm{kg}^{-1}$ étant observés à des pressions d'injection de $276 \mathrm{kPa}$ (40 livres au pouce carré).

Par comparaison aux bronchoscopes de calibre adulte, les bronchoscopes pédiatriques sont vulnérables aux petites variations de plusieurs facteurs. Par exemple, en plus du calibre de l'injecteur et du bronchoscope lui-même, la longueur et l'angle d'abord du tube de l'injecteur. la forme du bronchuscope et l'addition d'une succion, sont autant de facteurs pouvant modifier de façon significative les pressions maxima produites et, par conséquent. les volumes de ventilation.

Des volumes courants de 6 à $16 \mathrm{ml} \cdot \mathrm{kg}^{-1}$ ont été obtenus à des pressions d'injection de 138 à $276 \mathrm{kPa}\left(20 \mathrm{a} 40 \mathrm{lb} / \mathrm{po}^{2}\right)$ au cours de bronchoscopies diagnostiques effectuées chez 11 enfants âgés de six mois à trois ans, avec un système de Sanders $n^{\circ} 19$ utilisé avec des bronchoscopes de 3 à $6 \mathrm{~mm}$ de diamètre interne. Une ventilation adéquate a été obtenue même chez les enfants non curarisés. Ce dernier point est d'importance. si l'on considère que la plupart de ces patients présentent des problèmes complexes de voies aériennes, problèmes susceptibles de contre-indiquer l'emploi de curares.

On doit prendre bonne note que les résultats de ce travail s'appliquent au système d'injecteur Sanders $n^{\circ} 19$ et que toute modification apportée à ce système devrait d'abord être évaluée. 